\title{
Yvette Sánchez \\ La fiesta del Chivo: \\ el dictador dominicano como pantalla de proyecciones peruanas
}

Lo que Varguitas no dijo. Así reza el título de un libro escrito por la auténtica tía Julia, en 1983, como réplica a la novela publicada por Mario Vargas Llosa, en la que ella, ficcionalizada, desempeña un papel protagonista. Julia Urquidi Illanes, tía y ex mujer del autor peruano, se había tomado al pie de la letra la novela La tía Julia y el escribidor y quería rectificar unas cuantas cosas, reprochando a su sobrino y ex marido el haber tergiversado y falsificado las bases reales de su historia común.

La recepción de La fiesta del Chivo (Vargas Llosa 2000) ha tomado un rumbo parecido. Dentro (y fuera) de la República Dominicana, la novela sobre el ficcionalizado dictador Trujillo suscitó una gran polémica, sobre todo entre los historiadores de la Isla, de los que el peruano recibió una lluvia de reproches, además de una recriminación por plagio. Y las personas reales de ambos bandos, tanto los familiares del "Benefactor de la Patria" como los pertenecientes al clan de los tiranicidas, se quejaron de falsificación.

A pesar de que sea muy fácil para Vargas Llosa reaccionar a tales reprobaciones escudándose en la cualidad ficcional de sus novelas, lo que le permite aparentemente reclamar la absolución, no parece que se le pueda conceder carta blanca así como así. Me parece más bien un tema delicado, apropiado sobre todo para juristas, quienes, en aquellos casos donde se produzca una acusación, tendrán que investigar el posible perjuicio que determinadas obras de arte puedan causar al derecho a la integridad personal, lo que lleva a poner en tela de juicio la supuesta libertad y autonomía de creación. ${ }^{1}$ Es decir que el elogio a la mentira, el discurso sobre la "verdad de la mentira" no exonera auto-

1 Mi colega Thomas Geiser (1990) escribió su tesis de "habilitación" jurista sobre este tema. Y recientemente ha vuelto al tema en un artículo: "Kunstfreiheit und Persönlichkeitsschutz" (Geiser 2008). 
máticamente a Vargas Llosa de esta responsabilidad ética (y jurídica). Se dio hace poco un caso suizo de denigración de una persona, menos obvio y transparente, sin que la novela utilizara siquiera su nombre propio: el autor y la editorial tuvieron que renunciar a la tirada completa. Si una persona privada se reconoce en una obra de arte y se siente herida por la representación que se hace de ella, cabe contraponer $s u$ derecho básico a la intimidad con la libertad de expresión del artista; la ficción literaria no miente, siempre y cuando no perjudique al prójimo. El derecho privado se encarga de la protección de la persona perjudicada (en asuntos de verdad, privacidad, honor, nombre, historia vital, etc.), y ésta puede pedir indemnización o desagravio. Eso sí, el damnificado tendrá que preguntarse siempre si no se causa aún más daño haciéndolo todo público y exponiéndose quizás a la ridiculización. $^{2}$

Lo que Varguitas no nos dijo es cómo "miente", cómo crea una historia a su manera, mentirosa, a través del filtro ficcionalizador, cómo instrumentaliza la materia prima, cómo pergeña, cómo monta sus tramas y personajes a partir de personas reales y datos empíricos. ¿Hasta dónde (en su docudrama o novela histórica o historia novelada) se permanece fiel a los hechos históricos en torno a sistemas autoritarios?

Al escribir sobre el totalitarismo, Mario Vargas Llosa, quien afirma haber vivido las dos terceras partes de su vida en dictaduras ${ }^{3}$ y quien, en su candidatura a la presidencia del Perú, perdió contra Fujimori, habría concebido como demasiado burdo un ataque literario directo contra el antiguo rival político. Reprimió el ajuste de cuentas convirtiéndolo en una indirecta contra el odiado régimen de su patria. Como tema alternativo para una segunda novela sobre el dictador -después de Conversación en la Catedral-eligió la lejana isla cuya férrea dictadura ya había tenido en mente durante muchos años. De paso, la imagen de Fujimori, Montesinos y compañía, que ya cuando Vargas Llosa redactaba La fiesta del Chivo andaba bastante maltrecha, recibiría un leve daño (co)lateral, puesto que en los sistemas totalitarios hay toda una serie de mecanismos que resultan fácilmente inter-

2 Hasta ahora, no ha habido pleito en el caso de La fiesta del Chivo.

3 Según una entrevista que Regula Renschler le hizo al autor para el programa 52 beste Bücher (Radio Nacional Suiza el 17 de junio de 2001). 
cambiables. La proyección que suele comparar un conflicto interno con uno externo se muestra aquí como un mecanismo de defensa (para la fama personal), sin por ello perder el carácter de ataque no tan oculto.

La fiesta del Chivo es una de las mejores novelas de Vargas Llosa, muy bien construida y mostrando un meritorio intento de empatía con el pasado de la República Dominicana; el literato se documentó a fondo. Y el texto se presta para señalar un camino hacia la superación de cualquier pasado dictatorial (no echando demasiada tierra sobre los nefastos acontecimientos, sino poniéndolos al descubierto). En este sentido, Trujillo funciona como dictador emblemático. Se le pueden perdonar un par de irregularidades y deslices, así como algunos chatos estereotipos aplicados al pueblo dominicano, extraños en un poeta docto y que resultan más bien propios de un turista.

A pesar del gran esfuerzo realizado por informarse exhaustivamente sobre la historia dominicana, las proyecciones del autor peruano delatan repetidas veces su condición de foráneo ${ }^{4}$ y tampoco le sale demasiado bien a Vargas Llosa su ocasional intento de imitar el lenguaje regional, ya que salpica un habla suprarregional latinoamericana con unos (supuestos) dominicanismos. La protagonista totalmente ficcional se queda algo esquemática. Tampoco ayuda el hecho de que el autor esté endeudado con la crónica del historiador neozelandés Bernard Diederich (1978) titulada Trujillo. The Death of the Goat (o la de Robert Crassweller 1966: Trujillo: the Life and Times of a Caribbean Dictator). Todos estos puntos críticos ya han sido elaborados anteriormente por varios colegas. ${ }^{5}$

De momento, me limito a ilustrar la estrategia consciente de transferencia o proyección de Vargas Llosa y a mirar de cerca, por ejemplo a los personajes cortesanos del séquito del dictador Trujillo, deteniéndome en uno de ellos sobre todo.

4 Me limito a citar un solo ejemplo que muestra los estereotipos, a través de los que el autor peruano (con un sentido de la audición bastante delicado) percibe la vida de la isla caribeña hacia finales del siglo XX. "Algo en los dominicanos se aferra a esa forma prerracional, mágica: ese apetito por el ruido. ('Por el ruido, no por la música.')." (La fiesta del Chivo: 15)

5 Por ejemplo, Frauke Gewecke, en septiembre de 2001, en un Dossier de Iberoamericana ( $\mathrm{N}^{\circ} 3$, pp. 109-179), en colaboración con Sabine Köllmann y los historiadores Franklin Franco Pichardo y Roberto Cassá. Remito asimismo a la monografía sobre el género de Ana Gallego Cuiñas (2006). 
En la constelación de un régimen totalitario siempre está el malo, el esbirro, el que para disipar y pulir la culpa del dictador funciona como chivo expiatorio, elemento amortiguador, foco de todas las maldades. En la República Dominicana este papel le correspondía a Johnny Abbes García, en Perú a Vladimiro Montesinos.

El fujimorato, la democracia de mera apariencia, con un sistema de partidos más que cuestionable, la inoperancia del congreso, un régimen hipercentralista, problemas constitucionales (derechos humanos, doble reelección presidencial, etc., cf. Planas 1999) y reproches de corrupción y tortura hicieron dimitir a Alberto Fujimori desde Japón, y luego fue destituido por "incapacidad moral" el mismo año de la publicación de la novela de Vargas Llosa. Finalmente, nueve años más tarde, en abril de 2009, tras una larga huida, fue condenado a 25 años de cárcel.

Y para mantener a flote el sistema de poder, de vez en cuando hay que hacer un escarmiento con la caída en desgracia de un cortesano: el personaje de Agustín Cabral tiene un alter ego real, Mario Fermín Cabral, senador del trujillato, gobernador de Santiago nombrado por Trujillo en 1940, destituido en junio de 1941 y tomado preso por supuestas "graves acusaciones". Mario Fermín Cabral sufrió la humillación de dos meses de prisión, luego Trujillo lo liberó y lo reintegró a su círculo de colaboradores. Durante el fujimorato, este sistema de arbitraria caída en desgracia toma cuerpo igualmente en los generales Máximo Vera, jefe del mando antiterrorista, y Guillermo Bobbio, director de la Seguridad del Estado.

Tales paralelismos de personal del gobierno son demasiado obvios y se han repetido no pocas veces. Pero lo que Varguitas nunca dijo ni tampoco mencionó nadie de entre los historiadores dominicanos en la eterna discusión sobre la fidelidad a los hechos históricos y la ficción, facts and fiction, es un asunto bastante más interesante.

Se trata del enigmático Henry Chirinos, el constitucionalista beodo. Al escudriñar mis libros de historia dominicana, para averiguar a qué jurista feo y entregado al alcohol se refería Vargas Llosa al construir su personaje, no hallé a nadie en el séquito de Trujillo que se le pareciera y que tuviera alguna base real, documental.

Ni siquiera el prestigioso historiador dominicano Roberto Cassá, catedrático, miembro de la Academia de la Historia y director del Archivo Nacional ha resuelto el enigma, ni tampoco Pedro Conde 
Surla quien publicara en abril de 2001, en la revista cultural dominicana Vetas, su artículo "El Chivo de Mario Vargas Llosa". Al analizar a los "aduladores palaciegos" de Trujillo, Conde Surla afirma, sin acertar:

Otros, como Henry Chirinos, con nombres y apellidos inventados, y otros, como Balaguer, con nombres y apellidos reales. Balaguer, de cualquier manera es inconfundible y de poco o nada le valía el camuflaje de un nombre ficticio. [...] El misterio, en cambio, envuelve a Henry Chirinos. La gente de cierta edad se pregunta por Chirinos, los conocedores indagan sobre Chirinos y no lo identifican, porque Chirinos es, a todas luces, un prototipo, el prototipo de varios cortesanos. Su descripción corresponde probablemente a una mezcla de físicos y personalidades de cortesanos de la era: gordo como Fulano, sucio como Zutano, beodo como Mengano, etc. Chirinos es un poco todos, un mejunje, un cóctel, una batida de cortesanos (Conde Surla 2001: s.p.).

Pues no: Vargas Llosa no configuró su personaje según un sistema fragmentario o mosaico de retales, sino que muy hábilmente introdujo como polizón o pasajero clandestino de esta caterva de cortesanos de Trujillo a Enrique Chirinos Soto, abogado congresista, quien dirigiera las reformas constitucionales bajo Fujimori en el Perú.



Fuente: $<$ http://www.caretas.com.pe/ 1478/arequipa/44-1-c.jpg> (11.7.2011).

Como se puede ver en las fotografías, las referencias a su fealdad se corresponden con la vida real. Parece que el literato quiso saldar cuentas con quien antaño fuera el portavoz de su partido durante su candidatura a la presidencia y luego cambió al otro bando y se hizo fujimorista; el tal sujeto aún se había

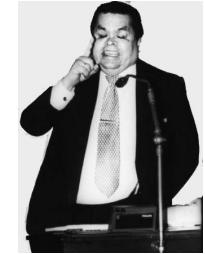

Fuente: <http://www.caretas.com.pe/ 1478/arequipa/44-1-c.jpg> (11.7.2011).

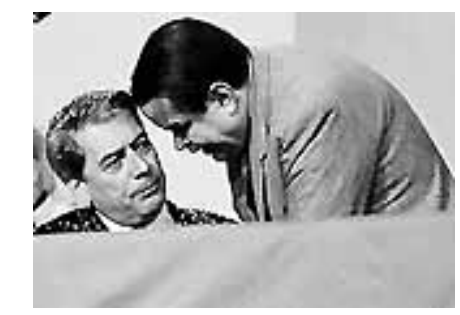

Fuente: $<$ http://www.caretas.com.pe /2000/1624/web/cartas/8-1-c.jpg>

(11.7.2011) 
permitido emitir comentarios racistas en la lucha electoral contra el inmigrante japonés, elogiando a $s u$ candidato, Vargas Llosa, por ser un "peruano de cuatro costados" (Laufer 2000: 175-176).

Al leer y analizar, hace un par de años, La fiesta del Chivo con los estudiantes, por pura casualidad y a través de la popular revista política peruana Caretas, di con un número del año 1997 que me mostró al Chirinos auténtico. Obviamente a los historiadores dominicanos (e internacionales) no se les ocurrió consultar el panorama político peruano (y así quitarse de encima, en un efecto relativizador, algo del peso de su pasado divulgado ampliamente por el autor peruano). En cambio, un periodista del suplemento SOMOS de El Comercio de Lima, Gustavo Faverón Patriau (2000), sí le hizo la pregunta al autor, a la que Vargas Llosa contestó ocultando de nuevo su camuflado arreglo de cuentas contra el auténtico Chirinos, tal como había negado públicamente (allá en 1983, en el teatro de Zúrich) haber leído el libro de su tía Julia.

A la pregunta del periodista sobre la pareja Henry Chirinos y Enrique Chirinos Soto, Mario Vargas Llosa contesta de una manera evasiva y sin ningún guiño: no se deja mirar las cartas, ni siquiera con la distancia de una década después de la publicación del libro.

No veo hace mucho a Chirinos Soto, no sé si se acerca o se aleja de mi personaje. Digamos que en todas partes hay coincidencias entre quienes son senadores al servicio de una dictadura. Se parecen. Hasta físicamente llegan a tener cierta afinidad, ¿no es verdad? (Vargas Llosa citado en Faverón Patriau 2000).

\section{"Miente" con más arte cuando escribe novelas ...}

La apología de la mentira que arrancó en la Antigüedad y vivió otro auge en el decadentismo la adoptó y cultivó Vargas Llosa a discreción. Si pienso en el concepto en conexión con la literatura, se me ocurren espontáneamente él, Harald Weinrich con su Linguistik der Lüge, ${ }^{6}$ o Antonio Muñoz Molina del fin de siglo pasado, y del XIX, El Marqués de Bradomín, Nietzsche u Oscar Wilde. La representación, ilusión y apariencia le parece a Antonio Muñoz Molina más verdadera y verosímil que la imitación mimética, chata de la realidad empírica

6 Weinrich (1966) cita el salmo (115,11), "omnis homo mendax" y el famoso sofisma cretense. 
(Muñoz Molina 1996: 312). El Marqués de Bradomín pronuncia todo un elogio de la mentira y la concibe como catalizadora del don fabulador, mientras que la luz de la verdad le parece insípida. En la misma época propagan la mentira como sustrato o motor creativo y seductor Nietzsche ${ }^{7}$ y Oscar Wilde, ${ }^{8}$ para quien el mentiroso es la base misma de la sociedad civilizada.

Vargas Llosa se inscribe en toda esta tradición reanudando el tema de la ilusión (o falsificación) artística, siguiendo la tesis de Baudrillard del simulacro, de la simulación "más verdadera que la verdad", asegurando en su ensayo El arte de mentir (citado en Sullà 1996), la base mentirosa de cualquier pieza ficticia. ${ }^{9}$ Las mentiras "llenan las insuficiencias de la vida", "documentan" nuestros "demonios", materializan "fantasmas", "nostalgias" "frustraciones", "deseos", "obsesiones" (Vargas Llosa citado en Sullà 1996: 274). ${ }^{10}$ Se aplican principios primarios tramposos y abiertamente declarados como tales y todo detector de mentiras se torna obsoleto.

La rehabilitación de la mentira apunta, si su efecto no es dañino, a los principios del fraude, la simulación, el camuflaje, el mimetismo, el placer lúdico y aliviador, a la mascarada del ser y parecer, según la carnavalización de Bajtin. El discurso de la mentira constituye un

7 Nietzsche expresa escepticismo respecto a la verdad comentando la general mentira lingüística y defendiendo la supremacía del Arte sobre la Vida. El arte declara la apariencia como apariencia, por ende no quiere engañar, es verdadero. "Der Intellekt, jener Meister der Verstellung, ist so lange frei und seinem sonstigen Sklavendienste enthoben, als er täuschen kann, ohne zu schaden, und feiert dann seine Saturnalien. Nie ist er üppiger, reicher, stolzer, gewandter und verwegener [...]" (Nietzsche 1980: 889). ["El intelecto, aquel maestro del disimulo, es libre y queda eximido de otras esclavitudes mientras logre engañar, sin hacer daño; entonces celebra sus saturnalias. Nunca es más suntuoso, rico, orgulloso, diestro y audaz" (trad. Y.S.)].

8 Oscar Wilde, en "The Decay of Lying" (1889), igualmente propugna liberarse de la "prisión" y el "fracaso" del realismo/naturalismo e independizar el Arte de la Vida o la Naturaleza "imperfectas", meras imitadoras (cf. Cansinos-Assens citado en Freixas 1997: 51).

9 Vargas Llosa (citado en Sullà 1996: 275) afirma que "sus órdenes artifíciales proporcionan refugio, seguridad, y en ellos se despliegan, libremente, aquellos apetitos y temores que la vida real incita y no alcanza a saciar o conjurar".

10 En el proceso transformador de la creación, se agrega a la vida, más o menos sutilmente, cierta dosis ilusionista de "modificación profunda" y verdad inherente. Por supuesto que ello depende de la preceptiva literaria de la verosimilitud, la "capacidad de persuasión, de la fuerza comunicativa de la fantasía" (Vargas Llosa citado en Sullà 1996: 273). 
código más de conducta despreocupada, corrosiva, disidente. Eso sí, frente a la mentira, cabe distinguir disimulos (usar de ardides), omisiones (el no decirlo todo) y engaños o falsificaciones (dejar al margen determinados hechos y sacar otros a relucir), ya que no son conceptos sinónimos. ${ }^{11}$

La verdad de las mentiras literarias se torna, en el contexto de $L a$ fiesta del Chivo, en el oxímoron opuesto, el político, "La mentira de la verdad" $" 12$ que señala la dialéctica de la mentira y el difícil y lento proceso transicional del esclarecimiento de la verdad en la postdictadura y así cobra una dimensión más existencial. La búsqueda de la verdad: el alejarse del ocultamiento y las mentiras resulta imprescindible para construir la postdictadura; a este problema se enfrenta cualquier Comisión de Verdad y Reconciliación que debe investigar los crímenes cometidos o fijar la dosis necesaria de amnistía e impunidad, como tributo de la mentira a la verdad. Ése es el trauma y el "sentimiento de culpa de una sociedad que está dispuesta, parcialmente, a vivir sin justicia y sin una conciencia moral adecuada" (Achugar 1992: 45). ¿Cuánta verdad aguanta la escritura postdictatorial? La mentira en política es un tema vasto, como lo afirma varias veces Hannah Arendt en Verdad y politica.

Las novelas de la dictadura reflejan la dialéctica entre verdad y mentira; son un campo de mutuo receptáculo en el lento proceso de afrontar traumas causados por sistemas totalitaristas y el intento de superación político-literaria de demagogias, en las que la mentira política utilitarista, dañina o maliciosa (con engaño intencionado) suele tener primacía.

La mentira (y las apariencias, manipulaciones, simulaciones, ilusiones, falsificaciones) pertenecen al lenguaje, por ende a efectos retóricos, tropos, equívocos, que suelen colarse en el discurso político. En general, la literatura y la política mantienen una relación estrecha, también en el terreno de la Academia. No solo las ciencias políticas, sino también las jurídicas, sociológicas, históricas e incluso las económicas utilizan cada vez más como material de estudio un corpus

11 Jacques Derrida define la mentira (distinguiéndola del error y lo falso) como intención de engañar al otro, de confundirlo, y propone una historia (desde la Antigüedad aristotélica) de distintas concepciones de la mentira.

12 Cf. el título de la contribución de Jochen Mecke en este tomo. 
literario, sobre todo en las universidades norteamericanas que es de donde viene el impulso. ${ }^{13}$

Quién sino Mario Vargas Llosa, un literato que siempre ha tenido puesto un pie en asuntos políticos, puede servir de nexo entre los dos territorios. Eso sí, Varguitas estará bajo nuestra vigilancia constante, por lo que no nos dice.

\section{Bibliografía}

Achugar, Hugo (1992): La balsa de la Medusa. Ensayos sobre identidad, cultura y fin de siglo en Uruguay. Montevideo: Trilce.

Conde Surla, Pedro (2001): "El Chivo de Mario Vargas Llosa". En: Vetas, 55 (<www.archivodevetas.blogspot.com/2006/07/el-chivo-de-mario-vargas-llosapedro.html >; 05.11.2008).

Crassweller, Robert (1966): Trujillo: the Life and Times of a Caribbean Dictator. New York: Macmillan.

Diederich, Bernard (1978): Trujillo. The Death of the Goat. Boston/Toronto: Little, Brown \& Co.

Faverón Patriau, Gustavo (2000): "Las dictaduras gobiernan nuestro inconsciente". En: El Comercio (Perú). Suplemento SOMOS, 13 de mayo (<www.laobradevargasllosa.com/entrevistas/vista18.html>; 05.11.2008).

Freixas, Laura (1997): Retratos literarios. Escritores españoles del siglo XX evocados por sus contemporáneos. Madrid: Espasa.

Gallego Cuiñas, Ana (2006): Trujillo: el fantasma y sus escritores. Historia de la novela del trujillato. París: Mare \& Martin.

Geiser, Thomas (1990): Die Persönlichkeitsverletzung insbesondere durch Kunstwerke. Basel: Helbing \& Lichtenhahn.

- (2008): "Kunstfreiheit und Persönlichkeitsschutz". En: Schwander, Ivo (ed.): Neuigkeiten im Kunstrecht. St.Gallen: Universität St. Gallen, Institut für Rechtswissenschaften und Rechtspraxis, pp. 9-29.

Laufer, Anke (2000): Rassismus, ethnische Stereotype und nationale Identität in Peru (Ethnologische Studien, 34). Münster/Hamburg/London: LIT.

Muñoz Molina, Antonio (1996): "El personaje y su modelo". En: Sullà, Enric (ed.): Teoría de la novela. Antología de textos del siglo XX. Barcelona: Crítica, pp. 311316.

Nietzsche, Friedrich ([1873] 1980): "Über Wahrheit und Lüge im außermoralischen Sinne”. En: Nietzsche, Friedrich: Sämtliche Werke. T. 1. München: dtv, pp. 875890.

13 En EE.UU. se han creado cátedras que trabajan exclusivamente según dicho método, por ejemplo, las de "Law and Literature". 
Planas, Pedro (1999): El Fujimorato. Estudio político-constitucional. Lima: s.e.

Renschler, Regula (2001): "Entrevista a Mario Vargas Llosa“. En: Radio Nacional Suiza DRS2: 52 beste Bücher, 17 de junio.

Sullà, Enric (ed.) (1996): Teoría de la novela. Antología de textos del siglo XX. Barcelona: Crítica.

Urquidi Illanes, Julia (1983): Lo que Varguitas no dijo. La Paz: Khana Cruz.

Vargas Llosa, Mario (1969): Conversación en la Catedral. Barcelona: Seix Barral.

- (1977): La tía Julia y el escribidor. Barcelona: Seix Barral.

- (1996): "El arte de mentir". En: Sullà, Enric (ed.): Teoría de la novela. Antología de textos del siglo XX. Barcelona: Crítica, pp. 269-275.

- (2000): La fiesta del Chivo. Madrid: Alfaguara.

Weinrich, Harald (1966): Linguistik der Lüge. Kann Sprache die Gedanken verbergen? Antwort auf die Preisfrage der Deutschen Akademie der Sprache und Dichtung vom Jahre 1964. Heidelberg: Schneider. 